\title{
The Research of Intelligent Irrigation Control System of Rice in Cold Region
}

\author{
$\mathrm{Na}$ Wang and Jinming Liu \\ College of Information Technology, Heilongjiang Bayi Agricultural University, \\ Daqing Heilongjiang 163319, China \\ yaya0107@sina.com
}

\begin{abstract}
In traditional way of rice irrigation in the Heilongjiang region, there are many problems such as huge consumption of water, complex wiring and cold water harm. To improve these problems, the intelligent irrigation control system based on PLC and configuration software is designed. The data acquisition and monitoring of water level and water temperature and other parameters are carried through the wireless transmission with PLC as the core, to decide whether irrigation and drainage. In order to solve the problem of cold water harm of rice, the water of Sun pool is heated by solar heating system. The use of solar panels and batteries for power supply of each part, solve the problem of large power loss. The application proves that the system has a positive effect on water-saving and improving the quality and yield of rice, improving the intelligent of irrigation system.
\end{abstract}

Keywords: rice, intelligent irrigation, soil moisture, PLC, water level

\section{Introduction}

China is a large agricultural country, and it is a serious water shortage country as well, Agricultural using accounting for about $70 \%$ of the total water consumption, and about $90 \%$ is used for agricultural irrigation. Rice is one of the most important food crops in china, the water consumption is one of the biggest irrigation crops, rice in many parts of the country with the method of traditional flood irrigation for irrigation, irrigation water waste is serious cases [1]. Therefore, the application of water-saving technologies in rice irrigation to solve the problem of the shortage of water resources is important. In recent years, with the development of modern agriculture, agricultural management mode is to develop in the direction of large-scale, intensive. Thus to promote the comprehensive, unified, large, intelligent irrigation system provides the necessary conditions

Cold rice intelligent water-saving irrigation control system is based on the climate characteristic of built three agricultural areas in Heilongjiang province and actual production conditions, which using wireless transmission technology, automatic control technology and computer technology and water saving irrigation are discussed combining research, implement according to the laws of rice water requirement characteristics and growth for automatic reasonable scientific irrigation. It improves the precision and the real-time irrigation, and improved utilization of water resources and agricultural output benefit as well. [2].

\section{Composition and Function of the System}

Heilongjiang province reclamation area is located in the Frigid Zone, most areas used of groundwater for irrigation. The groundwater's temperature is about $5^{\circ} \mathrm{C}$, however, the most suitable temperature for the growth of rice is between $14^{\circ} \mathrm{C} \sim 35^{\circ} \mathrm{C}$. So, direct irrigation is not conducive to the growth of rice [3]. This system is designed to saving 
irrigation water at the same time, adjust the water temperature to an appropriate value to increase rice production and improve rice quality.

This system contains the upper unit state monitoring module, PLC, wireless data transmission radio, the environment parameter acquisition module, the groundwater heating module and intelligent water-saving irrigation module. In order to make the system work reliably, the system utilizes both cable and solar panels for uninterrupted power supply. PLC collects data information and sends commands to communicate with wireless transmission station. The system overall structure is shown in Figure 1.

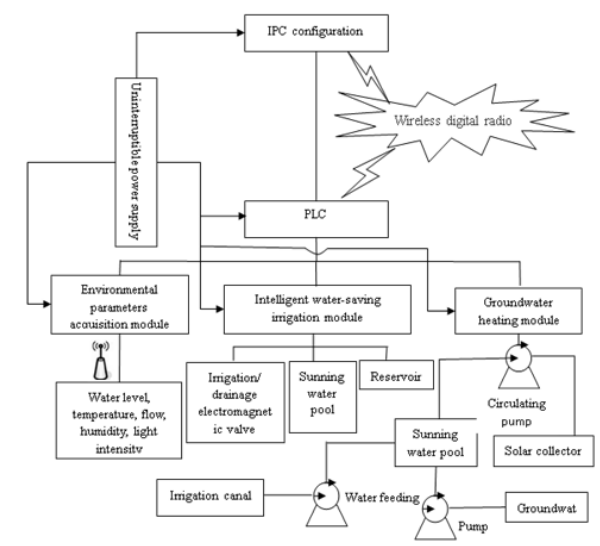

Figure 1. Overall System Structure Diagram

\subsection{PC Configuration and Monitoring Module}

PC using configuration software for real-time monitoring and management of various operation parameters, and at the same time in the form of a graph field of visual display, water level and water temperature of the drying tank level information. Through the upper computer can manually change some operation parameters, it sending the command of irrigation and drainage to control paddy water, and sending warmer water injection command control drying temperature of the pool water level etc. The upper computer and the PLC remote wireless monitoring network composed of a multipoint.

\subsection{PLC}

PLC (programmable logic controller) has many advantages of convenient use, simple programming, high performance price ratio, strong anti-interference ability, high reliability and easy function expansion has become the most important means of control, real-time control of industrial on-site. In this system, PLC is the core part of the whole control system, installed in at the scene of the farmland irrigation, use of wireless communications mode and distribution in the data acquisition equipment, the upper computer to realize data exchange of irrigation area [4]. On the one hand, PLC for data acquisition device sends commands to the executive device and collecting irrigation project in the equipment (such as solenoid valves) sends control command to open the closed; on the other hand, the PLC receives data from the underlying data acquisition device upload and PC transfer instruction and carries on the analysis, processing and storage.

\subsection{Wireless Data Radio}

In the water-saving irrigation control system, agriculture irrigation area is large, and the limitation of the regional environment, large-scale use of wired control approach is not only to the production of crops bring a lot of interference, and wiring complexity which wiring cost is very high, wireless control very good solution to this problem[5-8]. 
Wireless data radio use transparent way of working, responsible for the transmission of a machine to collect and monitor data center operating instructions. Wireless transceiver using transparent way of working, responsible for the transmission of the lower machine of the data acquisition and monitoring center issued the operation instruction.

\subsection{Environmental Parameter Acquisition Module}

Through the sensor to detect the water level, water temperature, light intensity, and traffic data information, all the environment parameters to the PLC, judged by performed by the PLC to determine the next steps.

\subsection{Groundwater Warming Module}

Heilongjiang province area's groundwater temperature is usually around $5^{\circ} \mathrm{C}$, direct irrigation will delay rice growing process, and decrease the rice quality. If only use sun sink temperature, it could not achieve the desired temperature in a short time. In the sun water pool set up large vacuum tube solar collectors, When the water temperature is below the lower limit value, using circulating pump of the water from the sun sink into the cycle to the heating tube heating, when the sun sink in the water temperature control in setting between the upper and lower, circulating pump stop working, when the temperature reaches the upper limit.

\subsection{Intelligent Water-Saving Irrigation Module}

PLC put the amount of water needed for growth period of rice water level sensor data with lattice Tanaka passed the comparative, to decide whether to electromagnetic valve opening and closing irrigation and drainage, irrigation or drainage on paddy field. Paddy field in excess water is discharged into the reservoir for storage, for the next irrigation cycle, so as to realize the automation of irrigation cycles.

\section{Design of Rice Intelligent Control Irrigation System in Cold Region}

This system realizes the automatic, semi-automatic and manual three irrigation methods. The main controller of the system is PLC. The data in sunning water pool and paddy are obtained by the temperature and humidity, water level, light intensity and other sensors, and which are transferred to PLC and PC configuration monitoring software. The system according to the related algorithm opens and closes irrigation solenoid valve, drainage solenoid valve and solar heating systems. Due to the command for some special reason to paddy irrigation or drainage, the one way by changing the parameter is settings to achieve semi-automatic irrigation and drainage, another way is open to irrigation solenoid valve or drainage solenoid valve on the PLC touch screen by staff to achieve manual irrigation and drainage.

\subsection{Hardware Design}

3.1.1. PLC Design: Based on a variety of PLC product performance, price comparison, the PLC control system with Mitsubishi. FX2N series has the advantages of small volume, high working reliability, high cost performance and module structure. At the same time, according to the expansion of the system need to be flexible.PLC and the external input and output devices, wireless digital radio and UPS connection relationship as shown in table 1 [9]. 
Table 1. PLC and Peripheral Connectivity

\begin{tabular}{|c|c|}
\hline PLC terminal & peripheral equipment \\
\hline Analog A0 & main channel flow meter \\
\hline Analog A1 & Nozzle flow meter \\
\hline Analog A2 & Outlet flow meter \\
\hline Analog A3 & Water level sensor \\
\hline Analog A4 & Teil moisture sensors \\
\hline Analog A5 & Light intensity sensor \\
\hline Analog A6 & Rain sensor \\
\hline Analog A7 & Solenoid valve opening position switch in place \\
\hline Switch X0-X5 & Solenoid valve closing position switch in place \\
\hline Switch X6-X13 & Open relay \\
\hline Switch Y0-Y5 & Close relay \\
\hline Switch Y6-Y13 & Wireless digital radio \\
\hline R 485 & \\
\hline
\end{tabular}

3.1.2. IPC Design: The IPC is Advantech's IPC-610, pre-loaded Factory Talk View with Rockwell company development based on the Windows operating system. It manages the various operating parameters and remote control of the irrigation system.

3.1.3. Wireless Digital Radio: The wireless digital radio of system is NISSEI ND250A[10].Its transmit power is $1 \sim 10 \mathrm{~W}$, and data transmission dedicated band is 220$240 \mathrm{MHz}$, automatic tuning, dual memory, never run frequency; Its operating temperature range: $-40{ }^{\circ} \mathrm{C} \sim+70{ }^{\circ} \mathrm{C}$; It has all kinds of perfect protective functions, such as the power supply reverse connect protection, transmitter "long hair" protection, antenna open circuit and short circuit protection, etc.; It adopts double VCO design, the start-up time of transmitter is less than $5 \mathrm{mS}$, transceiver fast conversion speed; Its power consumption is ultra-low, waiting for the current is only $50 \mathrm{Ma}$ (lower power saving mode and sleep mode power consumption is lower). Its bit error rate is very low: $\leq 10-7 @-105 \mathrm{dBm}$ $2.4 \mathrm{kbps}$. NISSEI ND250A transmission distance can be up to a few tens of kilometers, which satisfy the reliable wireless data transmission distance between remote configuration and monitoring module and PLC, PLC and each sensor.

3.1.4. Sensor: Water level sensor of the system is the BANNER T30U liquid level sensor. The BANNER T30U:The detection distance of $150 \mathrm{~mm} \sim 1 \mathrm{~m}$ and $300 \mathrm{~mm} \sim 2 \mathrm{~m}$,response time of $48 \mathrm{~ms}$ and $96 \mathrm{~ms}$, analog output $4 \sim 20 \mathrm{~mA}$, error of $\pm 2 \%$, working temperature of$20^{\circ} \mathrm{C}^{\sim}+70^{\circ} \mathrm{C}$, with reversed polarity and transient over-voltage protection, overload protection, short circuit protection, and other functions. Due to the topography and wind problem, each paddy field installs 10 water level sensors in different positions. T Take 10 for the final result of the average of sensor measured values of sensor is the final water level value of paddy. Temperature sensor of the system is BM100-D wireless temperature sensor. The BM100-D: measuring temperature $-40{ }^{\circ} \mathrm{C} \sim+150{ }^{\circ} \mathrm{C}$, measurement accuracy \pm $0.5^{\circ} \mathrm{C}$. BM100-D transmission mode is sent immediately when the temperature changes, otherwise sent once in 10 minutes. Humidity sensor of the system is MC-TS2100,range: 0 $\sim 100,-50-150^{\circ} \mathrm{C}$, resolution: $0.1 \%, 0.1{ }^{\circ} \mathrm{C}$, absolute error: $\pm 2 \%, \pm 0.1^{\circ} \mathrm{C}$, relative error: $\pm 3 \%, \pm 0.2{ }^{\circ} \mathrm{C}$. The solar light intensity is measured by the light intensity sensor, when it is less than 0.3 Lux, solar heating system stops working. The system uses GZD illumination system transmitter, measuring wavelength range: $380 \mathrm{~nm} \sim 730 \mathrm{~nm}$, accuracy: $\pm 7 \%$, temperature characteristics: $\pm 0.5 \%{ }^{\circ} \mathrm{C}$, measuring range: $0 \sim 200000 \mathrm{Lux}$. GZD has good linearity, good waterproof performance, high reliability, beautiful structure, installation convenience, strong anti-jamming capability, etc. 
3.1.5. Flow Meter: In paddy, the open flow meter is installed in the main canal and drainage, and electromagnetic flow meter is installed at the entrance to the grid fields, which is to compare the relationship between actual irrigation amount and required amount, and displacement. Open channel flow meter of the system is $\mathrm{HOH}-\mathrm{L}-01$ Doppler ultrasonic open channel flow meter, which can measure the average flow velocity, water depth, and water temperature at the same time. $\mathrm{HOH}-\mathrm{L}-01$ has the advantages of high measuring precision, no head loss, and it could not build a slot or weir and good anti-theft performance.

3.1.6. Electric Valve Actuator: In order to realize the remote control, irrigation and drainage, the system on the basis of common butterfly valve installed electric actuator. Electric valve actuators are mainly to receive and implement the control commands sent from the PLC, which is to control the switch valve, and which is to upload timing the valve switch information to PLC.

\subsection{Software Design}

3.2.1. The Design Of Irrigation Control Strategy: Control system according to the law of water requirement in different growth period of rice, the use of controlled irrigation technology respectively formulate the growth period of rice irrigation control strategy. Is given priority to with accumulation of the rain, only green rice paddies surface phase keep thin layer, other each growth period were no longer set up water. In tillering stage, the upper limit of Soil moisture is saturated, and the lower limit control in $60 \%$ of the saturated moisture content. In jointing-booting stage, the Upper limit of Soil moisture is saturated, and the lower limit is $80 \%$ of saturated water content. It is to adopt this method with dry days after the irrigation water again, rains not irrigation, rain drained. It is light control in heading-flowering stage. The upper limit of Soil moisture is saturated, and the lower limit of Soil moisture is $80 \%$ of saturated water content. In the milk stage, it is central control, and the lower control to $60 \%$ of the saturated moisture content. Rice fertility soil moisture control is standard as shown in Table 2 .

Table 2. Water Control Standard in Rice's Birth Stage

\begin{tabular}{|c|c|c|c|c|}
\hline Growth stages & $\begin{array}{c}\text { Water } \\
\text { level }(\mathrm{mm})\end{array}$ & $\begin{array}{c}\text { The lower } \\
\text { limit of Soil } \\
\text { moisture } \% \\
\text { ) }\end{array}$ & $\begin{array}{c}\text { The upper } \\
\text { limit of Soil } \\
\text { moisture }(\%)\end{array}$ & Rainwater storage depth \\
\hline Turning green & 5 & - & - & $5 \sim 25$ \\
\hline Early tillering & - & 100 & 80 & $0 \sim 50$ \\
\hline Mid tillering & - & 100 & 70 & $0 \sim 70$ \\
\hline Late tillering & 0 & 100 & 60 & $0 \sim 70$ \\
\hline $\begin{array}{c}\text { Jointing- } \\
\text { booting }\end{array}$ & - & 100 & 70 & $0 \sim 70$ \\
\hline $\begin{array}{c}\text { Tasselling- } \\
\text { flore }\end{array}$ & - & 100 & 80 & $0 \sim 20$ \\
\hline Milk ripe & - & 100 & 70 & 0 \\
\hline Yellow ripening & 0 & - & - & 0 \\
\hline
\end{tabular}

3.2.2. The Design of Power Supply System: Power supply part throughout the entire system to work; only enough power and stable voltage can ensure the stability of the whole system. The whole system uses two powers to supply, one is wired, a way of the solar power. Another is solar powered. In order to achieve low power consumption, the system use mostly solar power and battery. The output voltage of solar module is $24 \mathrm{v}$. At ordinary times, solar panels in the normal power supply to the battery charging at the same time. When solar power is insufficient, the battery ensures the required operating 
voltage of solar. The required voltage of the processor and various sensors and valves is different, the effect of the power supply module converted $24 \mathrm{v}$ into a voltage used for each chip [11]. The structure of the solar power system is shown in Figure 2.

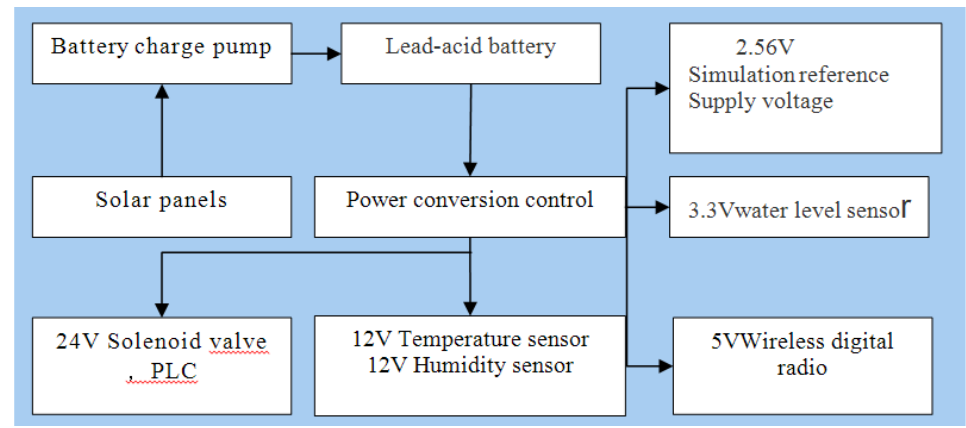

Figure 2. Structure of the Solar Power System

3.2.3. The Design of the Communication Protocol: System uses Mitsubishi FX2N series and computer link communication mode, namely the master-slave station protocol communication. Communication format: 8 bit data length, 1 stop bit, no parity bit. The entire network sends and receives data by using the same frequency. PLC station number will be unified numbering in communication.

The reading data format by the master computer sent to the slave computer is showed in Figure 3[12]. The content on the horizontal line is the data format for the master configuration monitoring software sent to the slave PLC. The data at the bottom of the horizontal line is response data from the slave PLC to the master configuration monitoring software. Data transfer order from left to right in turn. Each from the slave station has a unique number with two characters of hexadecimal. When the station number is $00 \mathrm{H}$, it means that the master station is PLC. PC number is fixed at FFH. The first component is only the data register D. Component data returned from the station PLC is represented by in four hexadecimal characters.

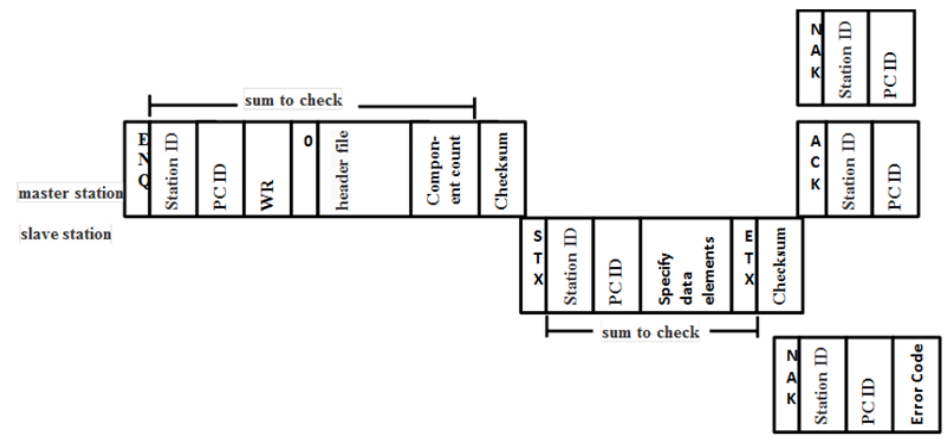

Figure 3. The Reading Data Format

The writing data format by the master computer sent to the slave computer shown in Figure 4. Code definition in data is basically the same with reading data format by the master computer sent to the slave computer. 


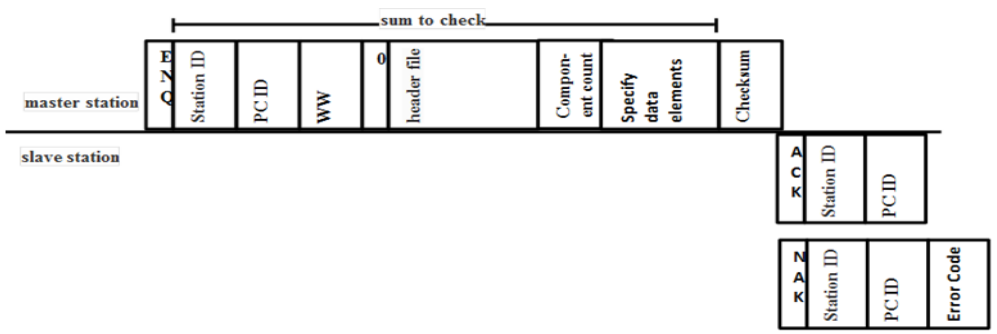

Figure 4. The Writing Data Format

3.2.4. The Design of the Main Program: Sun sink and solar water heater heating methods, it will achieve the required water temperature in each growth period of rice. The temperature of Sunning water pool is measured by the temperature sensor. When the water temperature is below the set thresholds, circulating pump continuously injected into the water from the sun sink into the solar collector to heat. Circulating pump stops working when the temperature reaches the upper limit. If the light intensity is lower than 0.3 , the solar heating system is shut down. Intelligent irrigation system according to the water level and soil moisture conditions in paddy decides whether irrigation water or drainage water. If the temperature of the irrigation water is lower than the critical value of the period in which the growth temperature, stop irrigation and start solar heating systems. Software flow chart is shown in Figure 5.

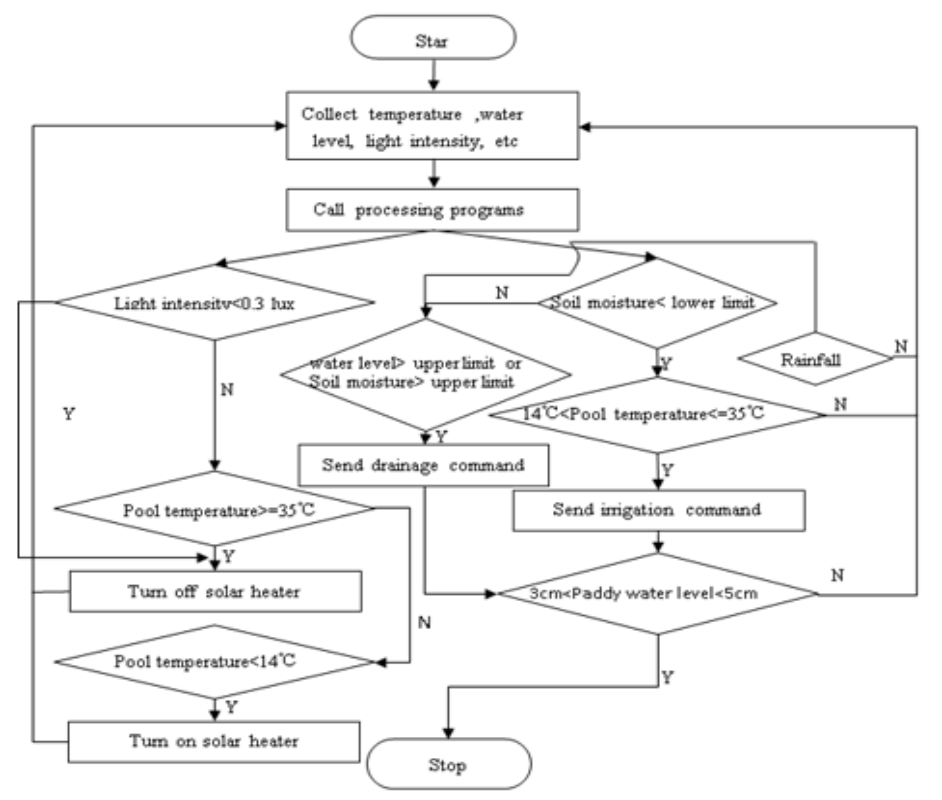

Figure 5. Flowchart of System Software

\section{Conclusion}

This system solves the problem of field power supply by using solar energy for PLC and sensor and electromagnetic valve. It breaks the limitations of wiring through wireless transmission way. This system with PLC as the core to realizes intelligent irrigation, implement well water temperature and remote monitoring, etc.

Figure 6 and Table 3 is statistical results after using the system. The comparison chart of water use efficiency and the comparison chart of irrigation water use efficiency are shown in Figure 6. The statistics of rice blast are shown in Table 3. 


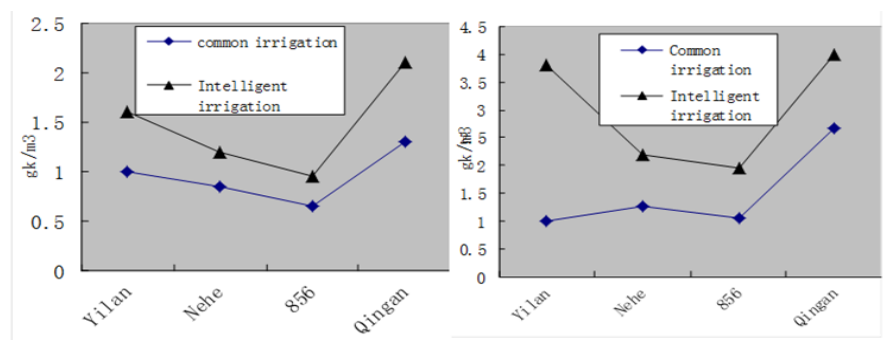

\section{Figure 6. Comparison Chart of Water Use Efficiency and Comparison Chart of Irrigation Water Use Efficiency}

Table 3. Statistics of Rice Blast

\begin{tabular}{|c|c|c|c|}
\hline Water Management Model & $\begin{array}{c}\text { Strain } \\
\text { rate }(\boldsymbol{\%})\end{array}$ & $\begin{array}{c}\text { Diseased leaves rates } \\
(\%)\end{array}$ & Disease index \\
\hline $\begin{array}{c}\text { Average number } \\
\text { of common irrigation }\end{array}$ & 6.5 & 6.8 & 6.8 \\
\hline $\begin{array}{c}\text { Average number } \\
\text { of intelligent irrigation }\end{array}$ & 3.7 & 4 & 2.9 \\
\hline
\end{tabular}

The results of application show that the application of rice in cold intelligent control system improve the rice quality, saving irrigation water, enhancing resilience of rice. For these tropical regions of large-scale rice production, the application of the system can get rid of the traditional agricultural production depend on the weather and use their experience production, embarking on the road of fine production, reducing labor use. The application results of this system is only in some regions in Heilongjiang province, and is obtained in field plot control conditions, its practical applications remains to be further validation.

\section{Acknowledgments}

The work is partially supported by the Teaching Reform Project of Heilongjiang Province of China (black teach high letter [2013] No. 351) under Grant No.365.

\section{References}

[1] Y. C. Kuang,Y. Shen, J. N. Duan and S. B. Yao, "Transactions of the Chinese Society of Agricultural Engineering", vol. 4, no. 27, (2011).

[2] R. W. Coates and M. J. Delwiche, "Trans of the AS ABE", vol. 52, (2009).

[3] J. W. Ji, W. W. Deng and Y. Y. Zhao, "Journal of Shenyang Agricultural University", vol. 3, no. 44, (2013).

[4] B. Ramazan, "ISA Transactions", vol. 2, no. 50, (2010).

[5] K.Yunseop, R. G. Evans and W. M. Iversen, "IEEE Transactions on Instrumentation and Measurement", vol. 7, no. 57, (2008).

[6] K. Yunseop, R. G. Evans and W. M. Iversen, "Journal of Irrigation and Drainage Engineering”, vol. 7, no. $57,(2008)$

[7] F. J. Pierce and T. V. Elliott, "Computers and Electronics in Agriculture", vol. 1, no. 61, (2008).

[8] J. Gutierrez, J. F. Villa-Medina, A. Nieto-Garibay and M. A. Porta-Gandara, "IEEE Transactions on Instrumentation and Measurement", vol. 1, no. 63, (2014).

[9] C. Liu, J. F. Shi and A. C. Li, "Journal of Agricultural Mechanization Research", vol. 11, no. 33, (2011).

[10] B. Stefano, “Ad Hoc Networks", vol. 8, no. 5, (2007).

[11] H. Q. Zhu, L. J. Yu, Y. H. Wang and Y. K. Jin, "Chinese Agricultural Mechanization”, vol. 2, no. 35, (2014).

[12] J. F. Shi, C. Liu, A. C. Li and S. J. Yi, "Hubei Agricultural Sciences", vol. 11, no. 52, (2013). 


\section{Authors}

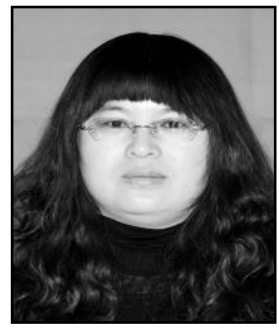

Na Wang, is currently a lecturer at Heilongjiang Bayi Agricultural University. She received master's degree in Shenyang University of Technology. Her research work is the application of information technology in agriculture.

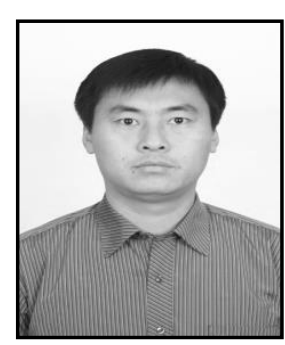

Jinming Liu, is currently a lecturer at Heilongjiang Bayi Agricultural University. He received master's degree in Yanshan University. His research work is the application of information technology in agriculture. 
International Journal of Smart Home

Vol. 9, No. 9 (2015) 